\title{
The Sub-Regional Value of Tourism in the UK in 2008
}

\author{
Coverage: UK \\ Date: 20 October 2011 \\ Geographical Area: European (NUTS) \\ Theme: People and Places
}

\section{The Sub-Regional Value of Tourism in the UK in 2008}

This report from the Tourism Intelligence Unit (TIU) at the Office for National Statistics examines the value of tourism in the regions and sub-regions of the UK. We consider both the supply and demand sides of tourism in this report and attempt to reconcile these at the regional and sub-regional levels for the whole of the UK. This report refers to 2008 and this is because the aim is to be consistent with the UK Tourism Satellite Account for 2008 published in May 2011.

\section{Introduction}

This report from the Tourism Intelligence Unit (TIU) at the Office for National Statistics examines the value of tourism in the regions and sub-regions of the UK for 2008 . Tourism is very much a demand side phenomenon and any analysis of the economic value, or contribution, of the sector is dependent on information on the spending of visitors. Clearly this expenditure is on products and services provided by industries but there is no sole 'tourism industry' but rather a set of industries, such as accommodation, food and drink serving activities, and passenger transport services. It is this set of tourism industries that constitute the supply side of tourism. The difficulty in measuring the value of tourism is determining what proportion of the output of these tourism industries is accounted for by the expenditure of visitors, in other words we need to reconcile the supply and demand sides of tourism.

The most complete treatment of these two elements of tourism is the Tourism Satellite Account (TSA), developed internationally by the UN World Tourism Organisation, OECD and Eurostat. The TSA uses a national accounts framework to determine the supply side of tourism, in terms of output and employment, before reconciling this information with demand side visitor expenditure data from overseas visitors to the UK, domestic overnight visitors, same day visitors, and the expenditure of UK residents travelling abroad before they depart the country (i.e. within the UK). The end result of this reconciliation is a set of tourism ratios for each tourism product, or service, which indicate the proportion of the value or output that is attributable to visitor expenditure. A complete TSA for the UK has been produced by the TIU for the reference date 2008 (the latest available national 
accounts data in the UK is for 2008). The analysis in this report aims to achieve a consistency with the national totals for demand and supply side of tourism published in this Tourism Satellite Account.

The aim of this research is to extend the TSA analysis to the regional and sub-regional (NUTS 1 , NUTS 2 and, where possible, NUTS 3 ) levels to give an indication of the value of tourism at these spatial scales. It is important to note that it is not possible to construct 'regional TSAs' in the UK without fully developed regional input output and supply use tables (IO\&SUT). What we can achieve however is a disaggregation of the main outputs of the TSA to the regional and sub-regional levels. This disaggregation is achieved through the use of the business survey data from the ONS and visitor expenditure data from tourism surveys which are used to give robust estimates of the supply and demand sides of tourism and, therefore, also allow for a reconciliation of the two at these spatial scales. We now detail the information pertaining to the demand and supply sides of tourism in 2008 before going on to analyse the direct value of tourism to the regional and sub-regional economies of the UK.

\section{The Supply Side of Tourism}

The main source of information used in relation to the supply side of tourism is the regional version of the Annual Business Inquiry ( $\mathrm{ABI}$ ) from 2008 which includes a scaling factor to ensure that data are representative at the regional level. The ABI is used to determine the output or GVA of the tourism industries. These tourism industries are derived from 40 five digit Standard Industrial Classifications codes for 2007 (SIC codes) which conform to the Standard Industrial Code of Tourism Activities (SICTA). Table 1 highlights the SIC codes used. 
The Tourism Industry SIC 2007 Codes

\begin{tabular}{|c|c|c|c|}
\hline Industry & SIC07 & Industry & SIC07 \\
\hline $\begin{array}{l}\text { Railway passenger } \\
\text { transport. }\end{array}$ & 49100 & $\begin{array}{l}\text { Transport Equipment } \\
\text { Rental }\end{array}$ & 77110 \\
\hline \multirow{2}{*}{$\begin{array}{l}\text { Road Passenger } \\
\text { transport }\end{array}$} & 49320 & & 77341 \\
\hline & 49390 & & 77351 \\
\hline \multirow[t]{2}{*}{$\begin{array}{l}\text { Water Passenger } \\
\text { transport }\end{array}$} & 50100 & $\begin{array}{l}\text { Sporting and } \\
\text { recreational activities }\end{array}$ & 77210 \\
\hline & 50300 & & 92000 \\
\hline \multirow{2}{*}{$\begin{array}{l}\text { Air Passenger } \\
\text { transport }\end{array}$} & 51101 & & 93110 \\
\hline & 51102 & & 93199 \\
\hline \multirow{6}{*}{$\begin{array}{l}\text { Accommodation for } \\
\text { Visitors }\end{array}$} & 55100 & & 93210 \\
\hline & 55201 & & 93290 \\
\hline & 55202 & $\begin{array}{l}\text { Country-specific } \\
\text { tourism characteristic } \\
\text { activities }\end{array}$ & 82301 \\
\hline & 55209 & & 82302 \\
\hline & 55300 & Cultural Activities & 90010 \\
\hline & 55900 & & 90020 \\
\hline \multirow{7}{*}{$\begin{array}{l}\text { Food and beverage } \\
\text { serving activities }\end{array}$} & 56101 & & 90030 \\
\hline & 56102 & & 90040 \\
\hline & 56103 & & 91020 \\
\hline & 56210 & & 91030 \\
\hline & 56290 & & 91040 \\
\hline & 56301 & & \\
\hline & 56302 & & \\
\hline
\end{tabular}

Table source: Office for National Statistics

Download table

XLS XLS format

$(14 \mathrm{~Kb})$ 
We have previously included real estate activity in this set of codes but, as in the UK TSA, we omit this from the current analysis as it severely over-inflates the supply side in relation to accommodation services. Real estate activity is likely to be more important in economies that rely on short term private letting of holiday homes. The problem here is that in the UK these SIC codes will include any letting of properties for tourism or non-tourism purposes which has a significant impact on the supply side analysis.

Other sources of information on the supply side include the ONS Supply and Use tables for 2008 which are used to derive estimates of the output of the tourism industries in purchaser prices as well as estimates of the regional economies on the same basis. This is important in the calculation of tourism ratios for each region and sub-region that allow us to determine the GVA directly attributable to tourism. ONS regional accounts data on GVA at the regional and sub-regional levels are also employed as the numerator for GVA of the tourism industries in each region.

In the next section we outline the steps taken in the analysis of the supply side analysis which, in itself, provides some useful data, for example the GVA of the Tourism Industries (GVATI).

\section{The Supply Side Analysis}

In this section we detail the steps taken to analyse the supply side information based on the SIC codes relating to the tourism industries. There are a number of distinct steps in this analysis and for a full treatment of the methodology see Buccellato et al, 2010. We aim to be concise and succinct in describing the steps taken but more methodological detail is available in the afore-mentioned publication.

\section{Step 1: Calculating the GVA of the Tourism Industries}

According to international recommendations on the compilation of the TSA (TSA: RMF, 2010), the Gross Value Added of the Tourism Industries (GVATI) is an important aggregate in an analysis of the economic contribution of tourism;

"Gross value added of the tourism industries (GVATI) simply sums the total gross value added of all establishments belonging to tourism industries, regardless of whether all their output is provided to visitors and of the degree of specialization of their production process. It leaves out the value added from other non tourism industries which outputs have been acquired by visitors or by others for their benefit" (TSA:RMF, pg. 47).

We can see from this that although an important first step in determining the contribution of tourism in an economy, GVATI is an imperfect measure as it doesn't distinguish between resident and visitor expenditure on the goods and services provided and it also excludes expenditure by visitors on goods and services provided by industries that are not part of the tourism industries, for example retail industries. As an indicator, both of demand and supply, gross value added of the tourism industries might therefore misrepresent the direct economic contribution of tourism. 
Nevertheless, GVATI is an important indicator in the context of this study as it allows us to determine the levels of output attributable to tourism industries in each region and sub-region which will then be used to apportion the total output in purchasers prices from the SUT in the next stage of the analysis.

In Figure 1 we show the percentage figure for GVATI at the regional level. In this chart a high figure means that a high percentage of regional output (represented by GVA) is accounted for by the tourism industries within that region. Figure 1 shows that the regions with the highest GVATI \% are London, the South East and Northern Ireland. This just reveals the relative importance of the tourism industries in terms of contributing to GVA within each of the regions. It does not relate this to visitor expenditure so this figure does not provide an accurate picture of the direct contribution of tourism to a region.

\section{Figure 1: GVATI\% in the Regions and Nations of the UK (2008)}

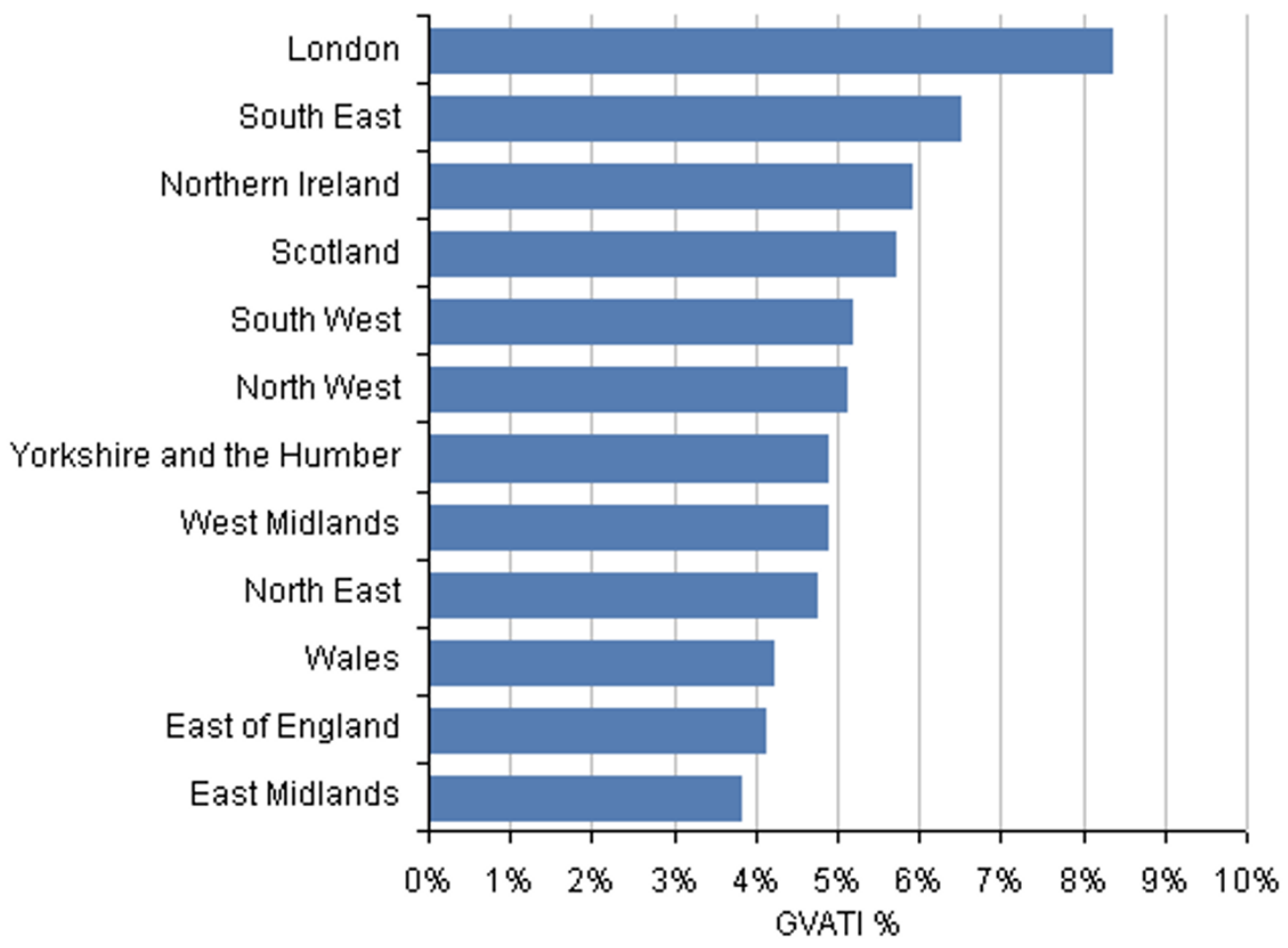

Source: Office for National Statistics

\section{Download chart}

\section{XLS XLS format}

$(24 \mathrm{~Kb})$

Similarly in Figure 2 we show the GVATI\% indicator in relation to the sub-regions (Nuts 2). As with the regions this is a useful indicator of the strength of the tourism industries within each subregion but shouldn't be considered as a measure of the economic contribution of tourism. Here Outer London, the Highlands and Islands, Surrey and East and West Sussex, North Yorkshire and Cornwall and the Isles of Scilly. 
Figure 2: GVATI\% at the sub-regional level in the UK (NUTS 2 top 20 shown) (2008)

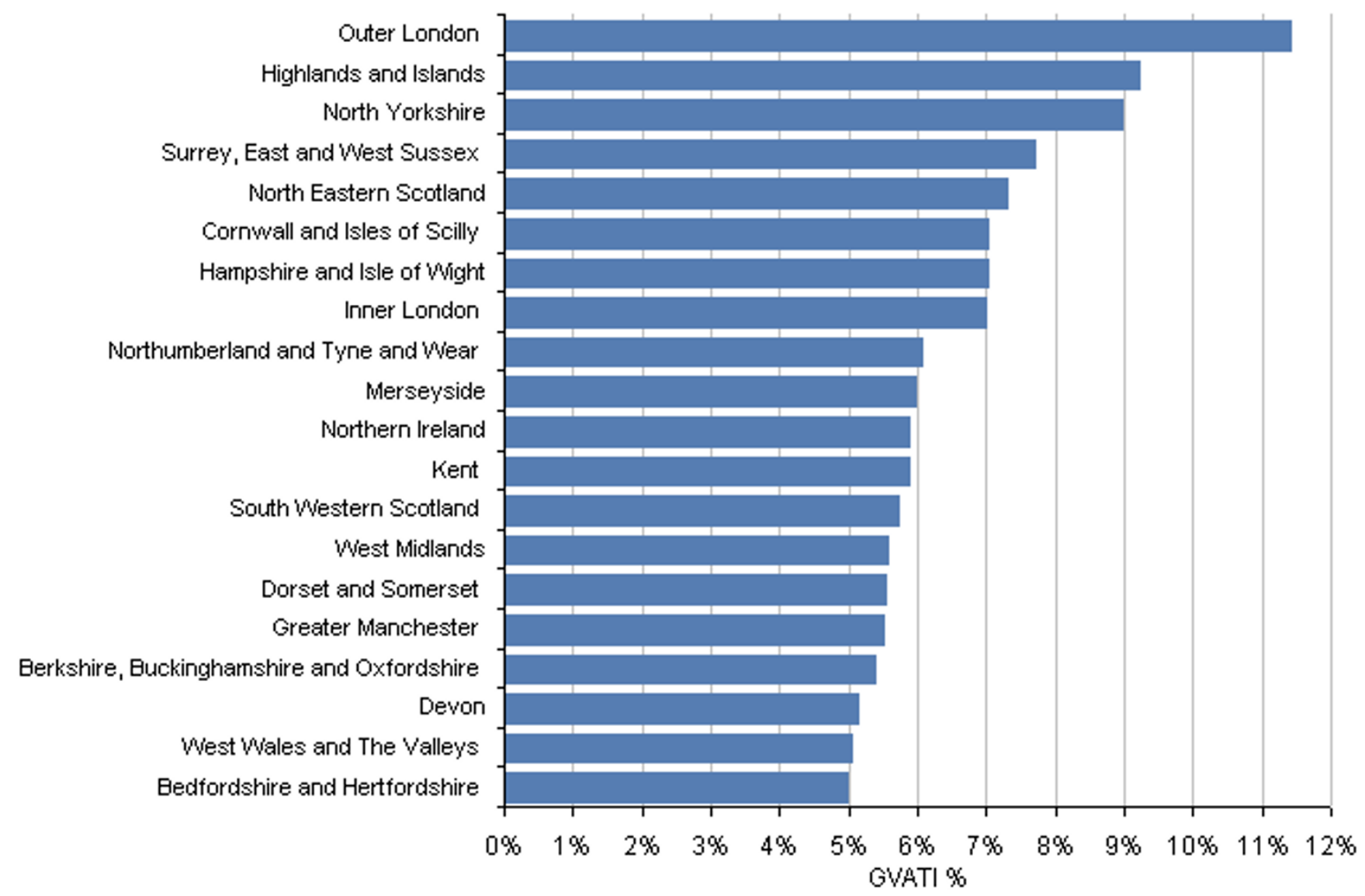

\section{Source: Office for National Statistics}

\section{Download chart}

\section{XLS XLS format}

\section{$(24 \mathrm{~Kb})$}

\section{Step 2: Balancing to Supply Use Tables Totals}

The next step in the analysis of the supply side data is to balance the GVA relating to the tourism industries within each region with the total supply of producers from the ONS Supply and Use tables. This is a necessary step as it allows for the eventual calculation of tourism direct GVA as we shall see later in this report. This stage of the analysis involves taking the shares of GVA in the tourism industries divided by the total GVA for each region, and then apportion this by gross value added at basic prices reported in the SUT.

The choice of using the SUT as the denominator allows us to obtain regional totals summing up to national UK figures, in particular those published in the UK Tourism Satellite Account. This results in regional and sub-regional tourism GVA and total GVA results all adding up to the UK totals published previously. This internal consistency is a key advantage of the methodology. 
In specific terms, the procedure can be described in two steps; first, we compute the ratio based on the $\mathrm{ABI}$ and conveying information about the overall distribution of tourism supply at basic prices across regions to apportion the total GVA at basic prices as reported in the SUT; and, second, we can then use the regional GVA-TI(\%) statistic to obtain the regional totals of tourism related regional supply of products at purchasers' prices. This figure can be used to determine the 'tourism ratio' or the proportion of the supply of tourism products and services that is driven by tourism demand or expenditure. In Table 2 we show the total supply for each Nuts 1 region and the equivalent figure for tourism industries, both at purchasers prices. The GVATI\% statistic is also shown here.

Table 2: The Domestic supply at purchasers prices for the regional/national economies and for the tourism industries

\begin{tabular}{|c|c|c|c|}
\hline NUTS 1 Regions & Total Supply & SUT-TI & GVATI \% \\
\hline & (£ billion) & (£ billion) & \\
\hline East Midlands & 206 & 8 & $3.8 \%$ \\
\hline East of England & 288 & 12 & $4.1 \%$ \\
\hline London & 700 & 58 & $8.4 \%$ \\
\hline North East & 107 & 5 & $4.7 \%$ \\
\hline North West & 315 & 16 & $5.1 \%$ \\
\hline South East & 472 & 31 & $6.5 \%$ \\
\hline South West & 253 & 13 & $5.2 \%$ \\
\hline West Midlands & 244 & 12 & $4.9 \%$ \\
\hline $\begin{array}{l}\text { Yorkshire and the } \\
\text { Humber }\end{array}$ & 233 & 11 & $4.9 \%$ \\
\hline England & 2816 & 166 & $5.9 \%$ \\
\hline Scotland & 269 & 16 & $5.7 \%$ \\
\hline Wales & 118 & 5 & $4.2 \%$ \\
\hline Northern Ireland & 75 & 5 & $5.9 \%$ \\
\hline Total UK & 3279 & 192 & $5.8 \%$ \\
\hline
\end{tabular}

\section{Download table}

\section{XLS XLS format}

$(16 \mathrm{~Kb})$

Before we describe the calculation of tourism ratios and the derivation of tourism Direct GVA, it is first necessary to detail the process of apportioning tourism demand across the regions and subregions of the UK. We briefly provide a note on tourism employment here before proceeding with this demand side analysis. 


\section{A Note about Employment}

We have not included an analysis of tourism employment in this publication and there is good reason for this. This publication represents the final stage of analysis of tourism data relating to 2008 which began with a supply side report which included an analysis of employment. This was followed by a detailed article on tourism employment including regional and sub-regional analysis before a full treatment of national tourism employment was included in the UK TSA for 2008. Following this publication and the emerging national accounts for 2009, the TIU can now turn to updating our supply side reporting and construction of the UK TSA for 2009, both of which will provide detailed analysis of tourism employment.

\section{The Demand Side of Tourism}

The tourism expenditure totals in this report are consistent with those in the 2008 UK Tourism Satellite Account ( TSA - published in May 2011). In this part of the report we briefly describe the sources for these totals and for the breakdowns by product and visit type that were part of the TSA.

We have use a number of methods to allocate the data in tables 1, 2 and 4 of Annex A of the TSA to regions, sub-regions and local areas (NUTS1, 2 and 3 areas). For each area there is also a breakdown by broad product group and visit type. The methods and data sources that we used to produce sub-regional estimates are also explained below.

It should be noted that sub-national results from the key surveys that we use are often based on small numbers of responses, if they are available at all. For annual surveys, therefore, we have combined three years' totals to provide estimates of the proportion of expenditure in each subnational area and then applied these proportions to the totals in the published TSA.

\section{Sources of Tourism Satellite Account Data}

A detailed explanation of the methodology for producing demand data in the 2008 TSA is included in the May 2011 release. The following is a summary:

\section{Inbound Tourism:}

The International Passenger Survey (IPS) provides an estimate of total expenditure by overseas visitors within the UK. For the 2008 TSA, the ONS' annual Supply and Use table was used to provide a breakdown by product, as it includes itemised non-resident household expenditure within the United Kingdom. Domestic survey data were used to provide more detail for some products.

\section{Domestic Overnight Visitors:}

The main source of information for this category of visit is the annual UK Tourism Survey. In the 2008 TSA we used a nine-product split of the results of this survey from Visit England, with information from day visit surveys providing further breakdowns of some products. The ONS 
annual Family Spending publication provided data on expenditure associated with second-home owenership.

\section{Domestic Day Visitors:}

Although a new day visits survey is currently being undertaken, results are not yet publicly available. We therefore obtained information from the most recent English Leisure Visits Survey (2005) and used this alongside the 2002-3 Great Britain equivalent and Northern Ireland 2003 TSA to produce estimates of spend by item that were updated to 2008 using multipliers based on annual Household Final Consumption Expenditure (HHFCE) data.

\section{Outbound Tourism Spend within the UK:}

The International Passenger Survey includes estimates of UK residents' expenditure on fares to overseas locations and on package holidays abroad. The latter was used to estimate the foreignholiday related travel agent expenditure. The TSA also used data on average spend at and enroute to airports from a 2005 survey by Morgan Stanley. Passenger numbers (for airports, sea ports and the Channel Tunnel) were used to provided a total estimate of spend and HHFCE multipliers updated this to 2008.

\section{Sources of sub-national expenditure breakdowns}

\section{Inbound Tourism}

Output from the International Passenger Survey (IPS) includes expenditure information for UK counties and unitary authorities, categorised by purpose (e.g. holiday, business, visiting friends and relatives). Using 2007-9 combined data, this geographical breakdown provides data for all regions, most sub-regions and some local areas.

To obtain estimates for all areas, counts of visits to towns and cities from the IPS and domestic surveys were used to allocate spend to specific NUTS2 or NUTS3 areas that are part of larger geographies. An expenditure trailer for the IPS was then used to divide the totals for each area into product totals, with household final consumption expenditure used to subdivide spend on some of these products. Finally, the sub-national proportions of spend produced by these processes were applied to the totals in the TSA

\section{Domestic Overnight Visitors}

Results from the UK Tourism Survey (UKTS) routinely include information about spend for the nine English regions and for Scottish and Welsh sub-regions. Visit England recently produced an analysis of the UKTS for 2007-9 with expenditure data for holiday and non-holiday purposes for English local authorities and we used this with some amendments to provide sub-national estimates of spend.

The sub-regional Scottish and Welsh data were further subdivided using data from the International Passenger Survey to give information for all NUTS2 and NUTS3 areas in these countries, again broken down into holiday and non-holiday spend. This split was used to estimate total spend by product in each area, taking into account the differing patterns of spend of holidaymakers and other 
visitors. The sub-national data were converted into proportions and then applied to the totals in the TSA.

For expenditure on second homes, the proportions of holiday homes / second accommodation in each area in the 2001 Census were applied to the TSA total in table four of the May 2011 release.

\section{Domestic Day Visitors:}

Although the English Leisure Visits Survey was used to provide estimates of total expenditure in 2008, it is not suitable for producing sub-national data. Instead we used information from the Great Britain Leisure Visits Survey (GBLVS) which covered 2002-3 and had detailed regional spend data and sub-regional visit data, including the number of visits during which particular products were purchased. We combined these to provide sub-national estimates, using other sources to provide information for the handful of areas where the NUTS definitions do not match the geographies in the GBLVS.

The sub-national data in the GBLVS include estimates of expenditure by product and we have, therefore, used this to produce a table of proportions of spend, incorporating Northern Ireland data from its 2003 TSA. These proportions were then applied to the 2008 totals.

\section{Outbound Tourism Spend within the UK:}

For this report we have assigned expenditure at and en-route to overseas holiday destinations to the location of the departure point, using passenger numbers to provide these estimates. Because the International Passenger Survey (IPS) does not include data for all airports or sea ports, we have only used this source for a geographical breakdown of Channel Tunnel passenger information. For airports we used Civil Aviation Authority data, with Department for Transport (DfT) statistics for sea ports. The proportions of passengers at each airport, sea port or Channel Tunnel departure point were applied to the TSA totals in table two of the May 2011 release.

We have also assigned expenditure on air, ferry and channel tunnel fares to the departure point within the UK. We used IPS fare spend data for outbound air and channel tunnel travel, with an adjustment to the former to include less busy airports not covered by the IPS. We used DfT passenger numbers to allocate ferry spend between sea ports.

Expenditure on travel agents fees for overseas visits has been allocated to the residence of the purchaser. We used regional proportions of weekly expenditure on package holidays abroad from the ONS' annual Family Spending publication. These data were sub-divided using estimates of the number of households from ONS and mean income from HMRC.

\section{The Demand Side Analysis}

The total value of internal tourism consumption in the 2008 UK TSA was $£ 113.7$ billion. Around 43 per cent of this related to domestic day visitors, almost 24 per cent was within the UK on outbound 
travel, over 19 per cent related to domestic overnight visitors and the remaining 14 per cent was from overseas visitors to the UK.

About a fifth of tourism expenditure in the UK in 2008 related to food and drink serving services with just under 12 per cent on accommodation. Passenger transport services received 19 per cent of expenditure (including air fares to overseas destinations) and cultural, sporting and leisure activities about 5 per cent. The remaining 44 per cent of tourism expenditure was on other products, including retail and personal transport costs.

\section{Tourism Expenditure by Region}

As figure 3 shows, around 40 per cent of total 2008 expenditure was in London and the South East. Spend relating to outbound travel was particularly prevalent in these areas, with around 56 per cent of the total, reflecting the large proportion of UK outbound airport passengers flying from Heathrow and Gatwick as well as the ferry and channel tunnel departures from these two regions.

These two regions also received about a third of expenditure on domestic day visits, reflecting a combination of their high populations (26 per cent of the UK total) and the large number of days out to London from elsewhere in the UK. In addition, over half of expenditure by overseas visitors in the UK was in London. For domestic overnight stays, however, the South West of England and Scotland received the highest expenditure, 18 per cent and 13 per cent of the UK total, respectively. 
Figure 3: Estimated Tourism Expenditure 2008 ( $(\mathrm{m})$ by UK NUTS1 Area and Visit Type

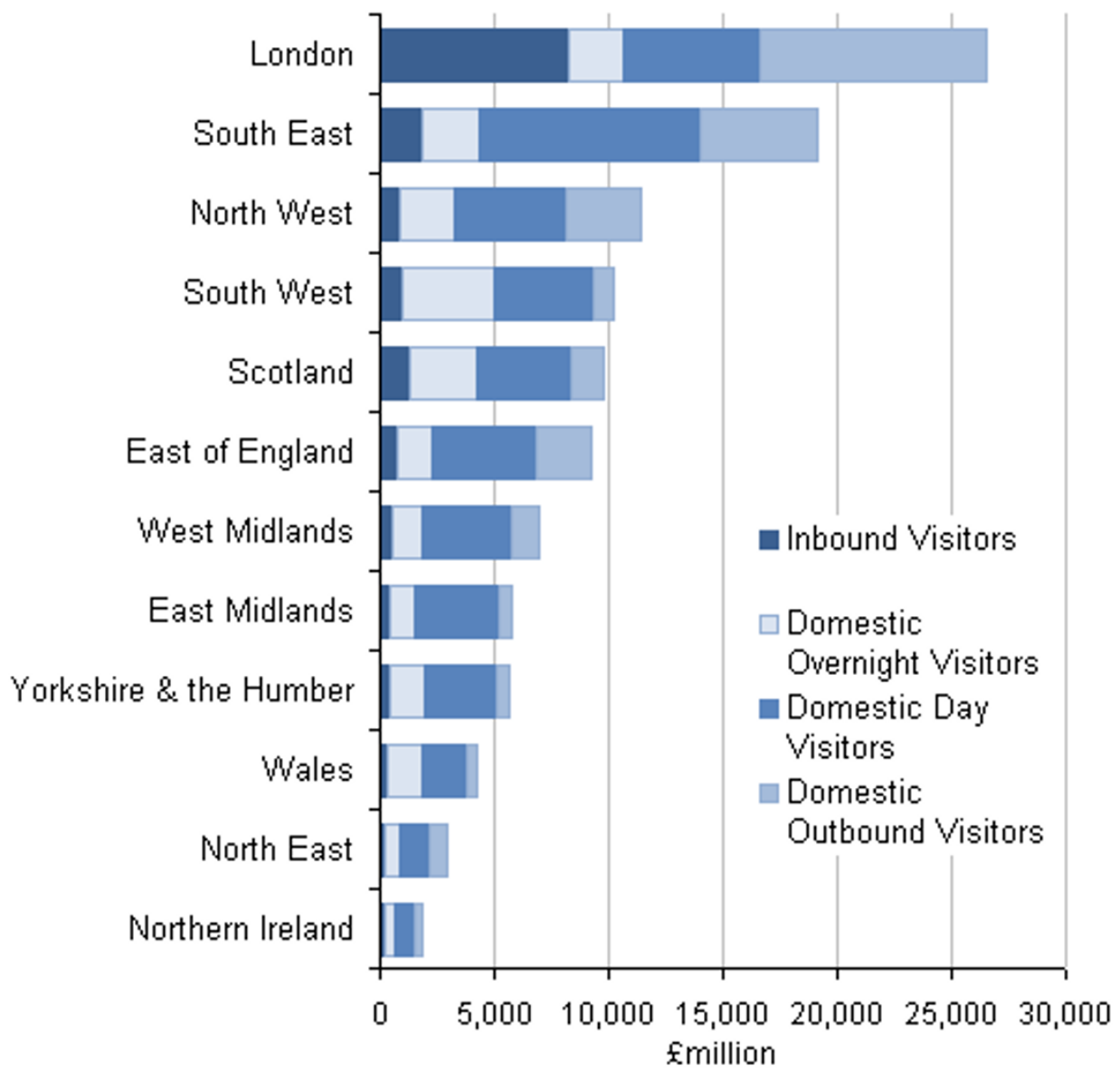

Source: Office for National Statistics

Download chart

\section{XLS XLS format}

$(21 \mathrm{~Kb})$

Regional breakdowns of total expenditure by product type in figure 4 highlight how spend on passenger transport is particularly prevalent in London and the South East but is not of the same level of importance in other regions. 


\section{Figure 4: Estimated Tourism Expenditure 2008 (£m) by UK NUTS1 Area and Product}

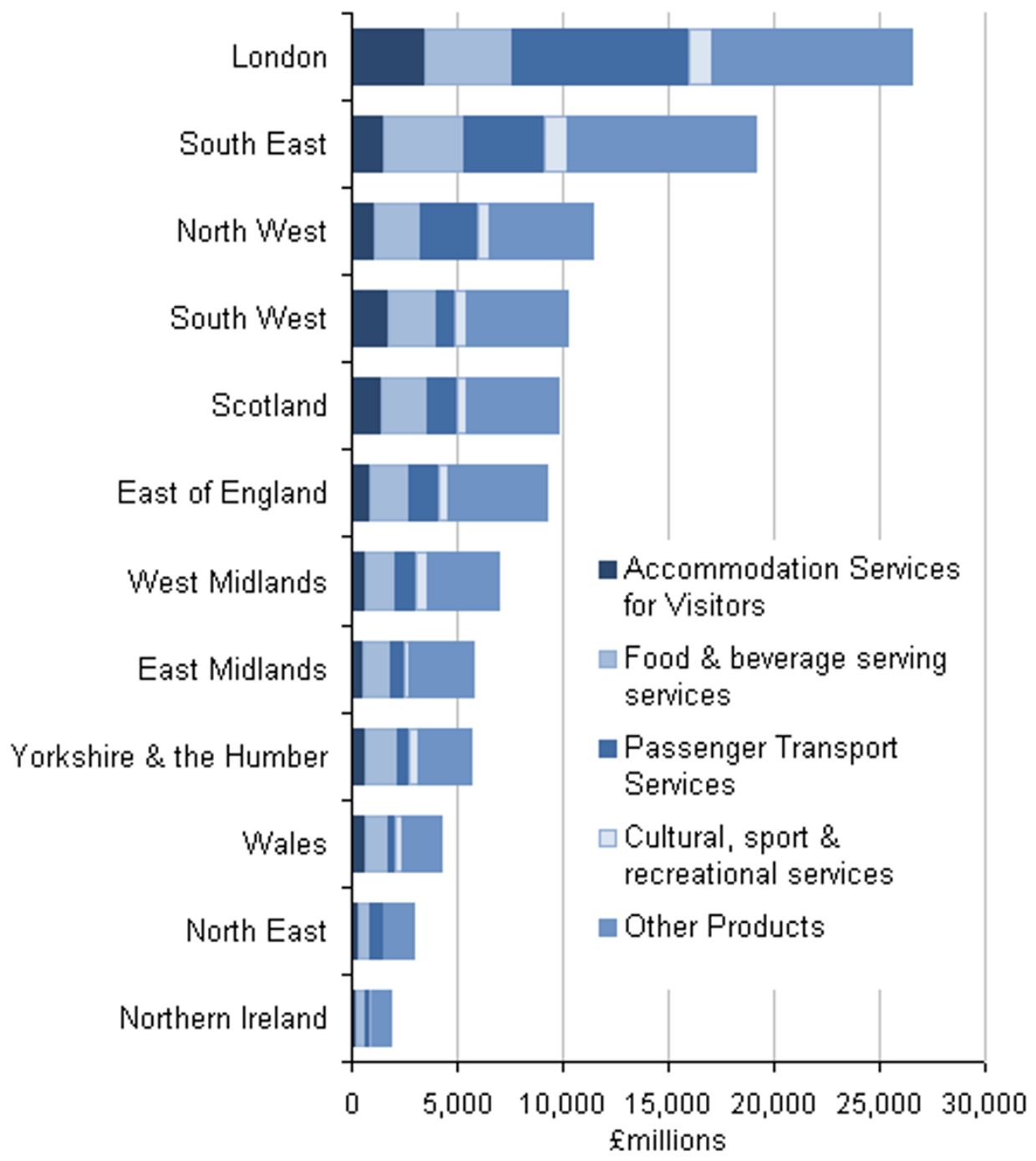

\section{Source: Office for National Statistics}

\section{Download chart}

\section{XLS XLS format}

\section{$(21 \mathrm{~Kb})$}

\section{Tourism Expenditure by Sub-Region}

NUTS2 data in figure 5 illustrates how types of visitors contribute to overall expenditure in UK NUTS2 areas (sub-regions). In areas with busy airports, domestic outbound expenditure is, not surprisingly, very prevalent. Domestic day visit expenditure is particularly important in areas that include major conurbations or are relatively close to London and the South East. On the other hand, the areas outside Inner London with the highest tourism expenditure on accommodation are fairly distant from London: Cornwall \& Isles of Scilly, Eastern Scotland, Devon and West Wales \& the Valleys. 
Figure 5: Estimated Tourism Expenditure 2008 ( $(\mathrm{m})$ by UK NUTS2 Area and Visit Type (top 20 ranked NUTS 2 regions)

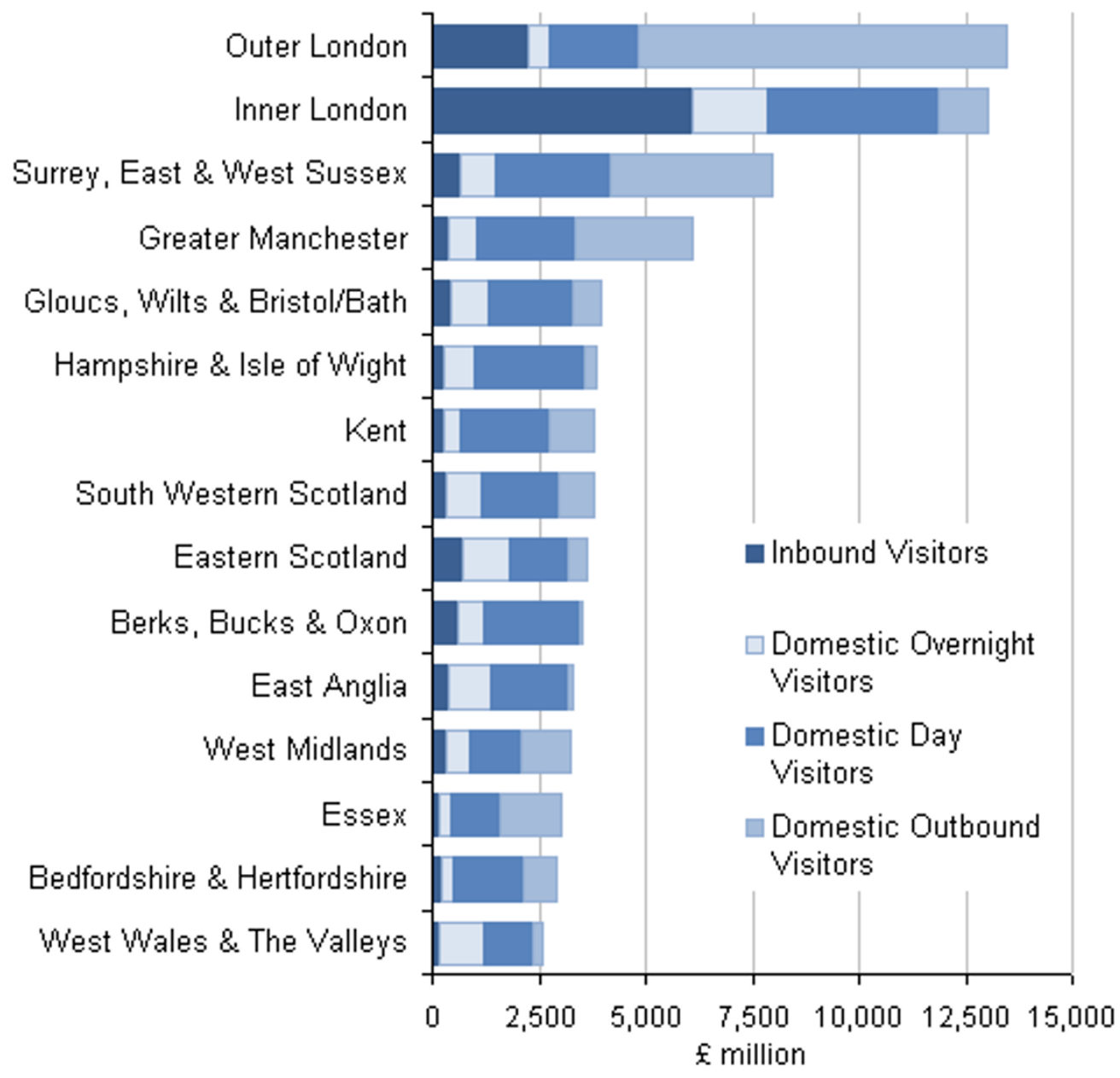

Source: Office for National Statistics

\section{Download chart}

XLS XLS format

$(21 \mathrm{~Kb})$

Figure 6 illustrates the 40 NUTS3 areas with the largest estimated tourism expenditure if spend on outbound travel is excluded (out of 128 in Great Britain). Total expenditure is much larger in Inner London West than anywhere else in the UK. As with NUTS2 areas, spend by domestic overnight visitors is more important in locations that are some distance from London and the South East. 
Figure 6: Estimated Tourism Expenditure 2008 ( $(\mathrm{m})$ by UK NUTS3 Area and Visit Type (top 20 shown)

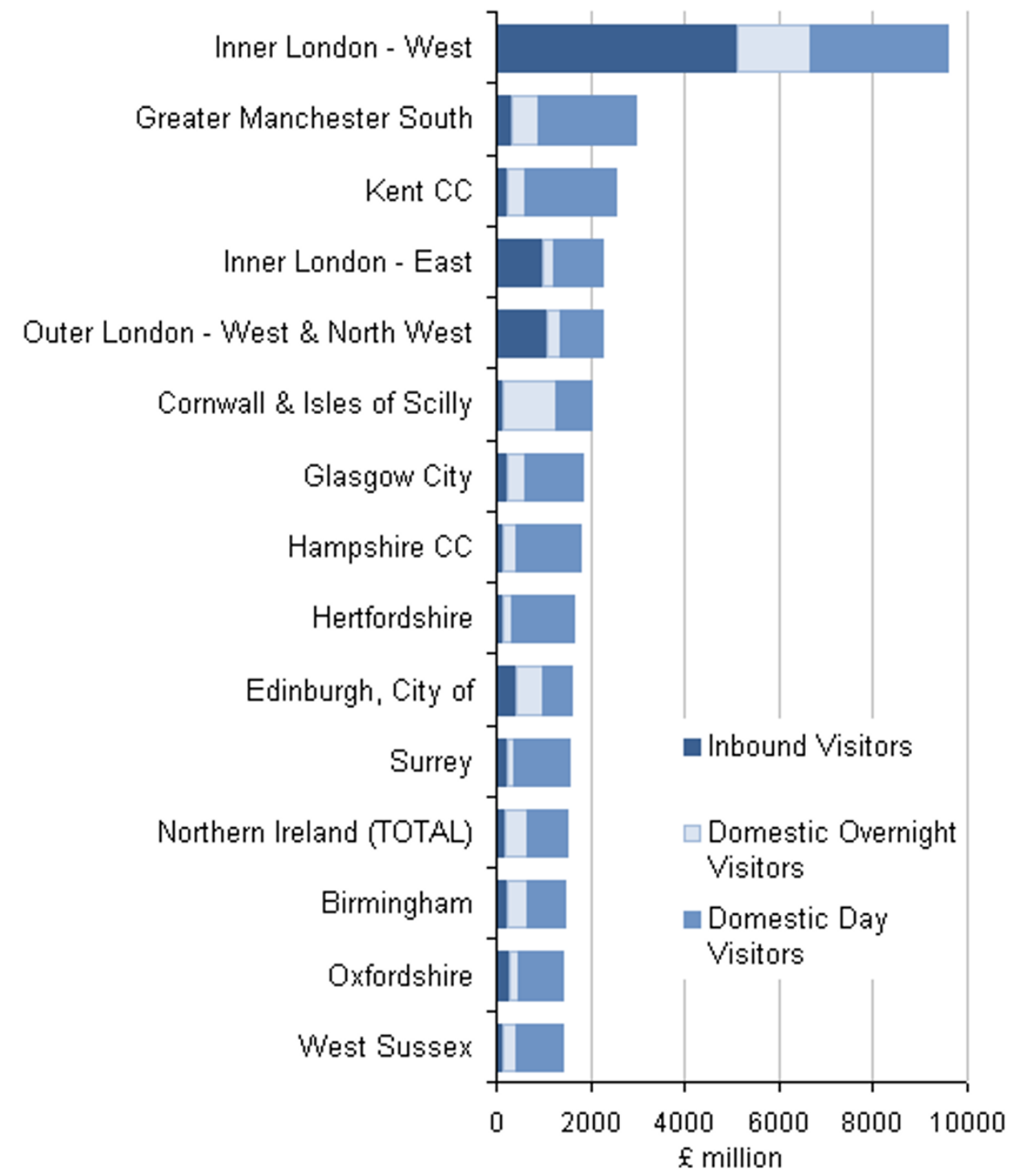

Source: Office for National Statistics

\section{Download chart}

XLS XLS format

$(21 \mathrm{~Kb})$

\section{Reconciling Supply and Demand}

Having presented the figures for both the supply and the demand sides of tourism we can now proceed to reconcile them. Again the detailed methodology can be found in Buccellato et al, 2010. In simple terms we need to know how important tourism demand is in explaining the output of individual regions. We can determine this by calculating a 'Tourism Ratio' for each region or sub 
region. This statistic is the result of dividing the total demand (i.e. visitor expenditure) by total supply in each region (which is the total domestic supply at producer prices from the SUT - see Table 2).

The Tourism Ratio itself represents a good measure of the economic importance of the tourism sector within regions, as it shows the relationship between tourism demand and supply, in other words the importance of tourism expenditure in driving output in these areas.

Figure 7 shows the Tourism Ratio by region (NUTS 1) and Figure 8 at the sub-regional level (NUTS 2). The South East and South West have the highest tourism ratios but there are a number of regions with ratios above $3.5 \%$ (which is the UK Total). At the sub-regional level we would expect tourism to have a dominant role in driving output in some regions and Figure 8 shows this clearly in relation to Cornwall and the Isles of Scilly and the Highlands and Islands of Scotland in particular.

\section{Figure 7: Tourism Ratios for the regions and nations of the UK in 2008 (NUTS 1)}

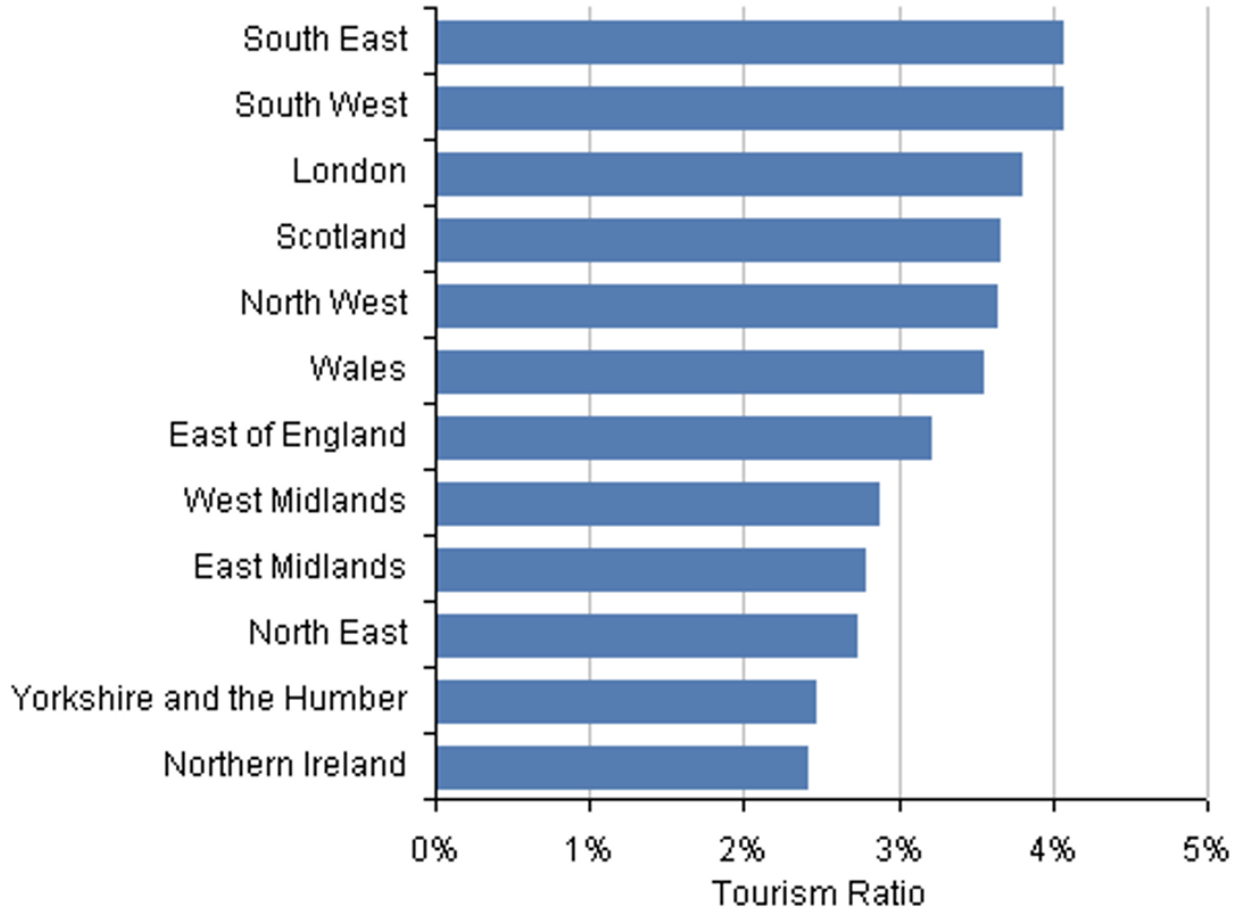

Source: Office for National Statistics

\section{Download chart}

\section{XLS XLS format}

$(24 \mathrm{~Kb})$ 
Figure 8: Tourism Ratios for the sub-regions of the UK (NUTS 2 regions top 20 shown) in 2008

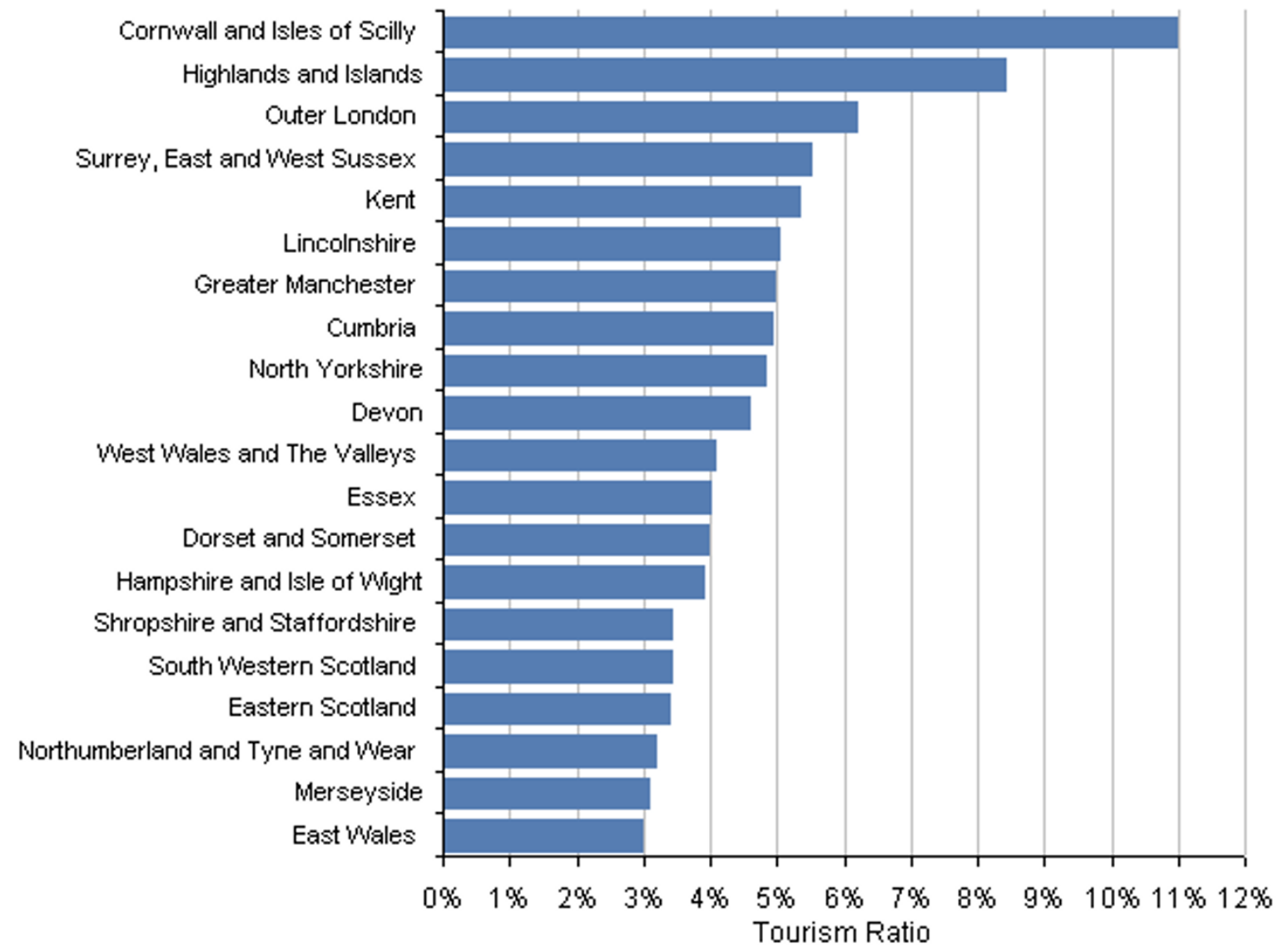

Source: Office for National Statistics

\section{Download chart}

\section{XLS XLS format}

$(24 \mathrm{~Kb})$

The Tourism Ratio is an important statistic in terms of this analysis because it allows for the calculation of Tourism Direct GVA (TDGVA) for each region and sub-region. This is achieved through a simple multiplication of the Tourism Ratio and the total GVA of each region in current prices. The TDGVA statistic is a key aggregate in tourism and is also derived in the Tourism Satellite Account. It should be noted here, however, that in the TSA we calculate the TDGVA differently by calculating tourism ratios for each tourism industry (and non tourism industries as a whole) and then applying this to the GVA of those industries in current prices. Summing those fractions of GVA across the industries will give us TDGVA. In this regional and sub-regional analysis we are not able to reproduce the Supply and Use Table supply side information for each industry at a regional and sub-regional level, so we have to calculate TDGVA differently by applying a tourism ratio to the whole region supply (which includes tourism and non tourism industries) rather than on an industry by industry basis. This results in a lower total TDGVA figure in the current study than in the UK TSA (44.9 billion here versus 47.1 billion in the TSA) and this is a direct result of the necessity of using a less sophisticated methodology at the regional and sub-regional level. In practice, we are losing 
some of the detail in terms of the influence of certain industries individually within regions but we are still capturing the overall impact of the tourism industries (and non-tourism industries) that are providing products and services to visitors.

In Figure 9 we display the TDGVA for the regions and nations of the UK (NUTS 1) and in Figure 10 the same TDGVA figures are presented at the sub-regional (NUTS 2) level. It is clear that London has a dominant position in terms of TDGVA, followed by the North West, South West and Scotland and this reflects the size of the host economy to some extent but also the role of major airports and other major ports which becomes clearer when we look at the sub-regional figures where Surrey and East and West Sussex has the third highest TDGVA which is partly explained by the presence of Gatwick airport.

\section{Figure 9: Tourism Direct GVA in regions and nations of the UK in 2008}

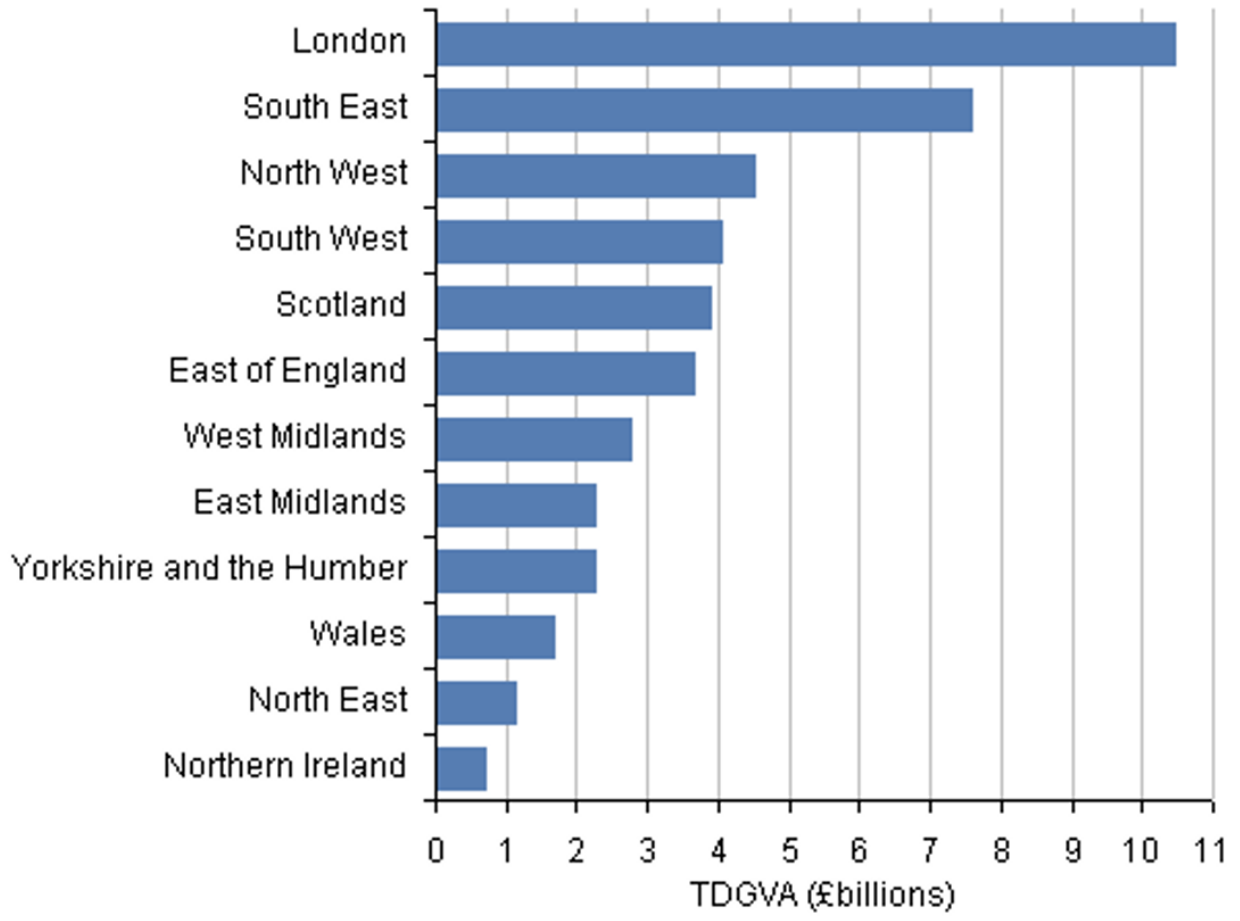

Source: Office for National Statistics

\section{Download chart}

XLS XLS format

$(24 \mathrm{~Kb})$ 
Figure 10: Tourism Direct GVA in sub-regions (NUTS 2 areas top 20 shown) of the UK in 2008

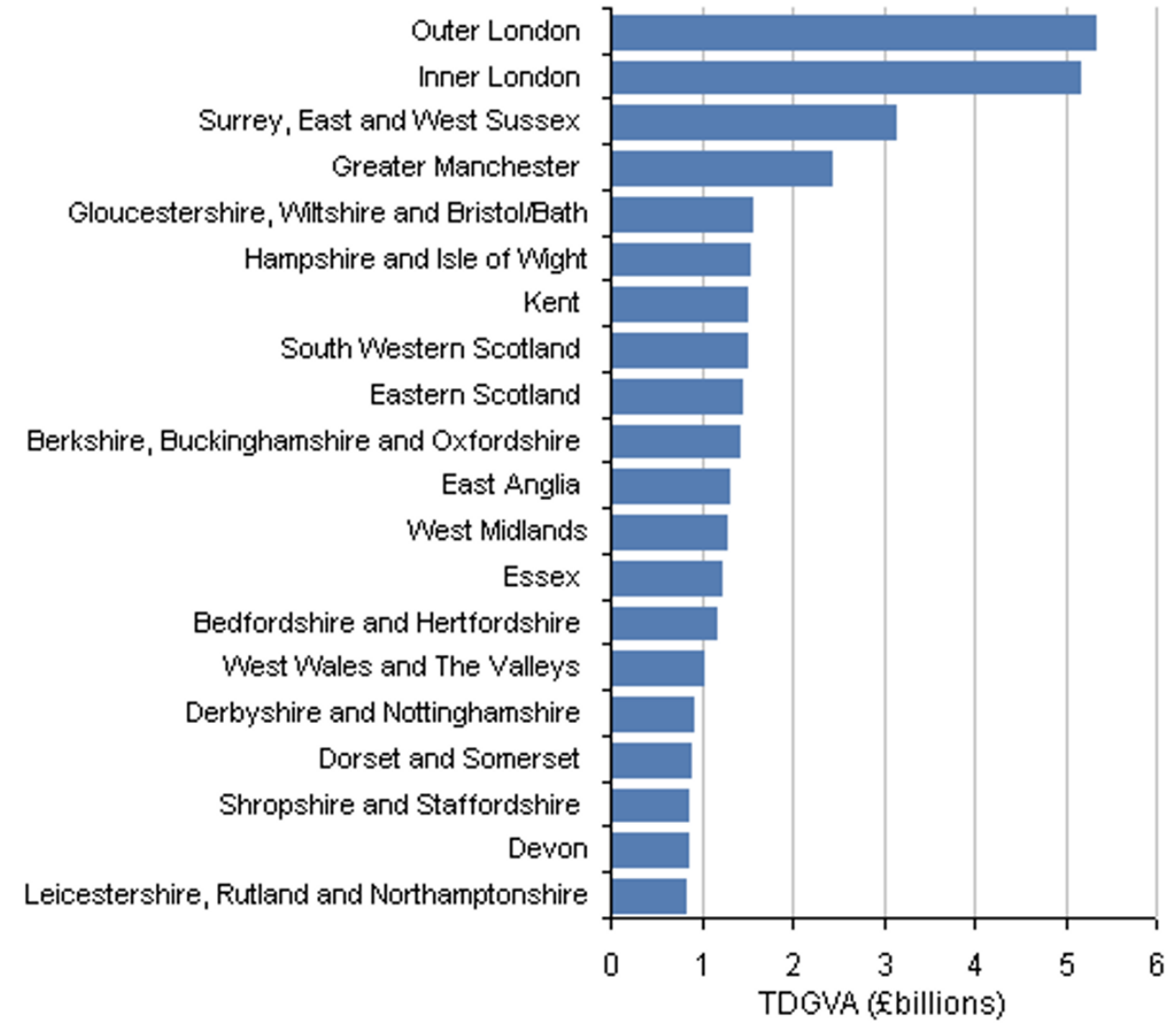

Source: Office for National Statistics

\section{Download chart}

\section{XLS XLS format}

$(24 \mathrm{~Kb})$

At this point it is worth recalling that the demand data or visitor expenditure information also includes the domestic outbound visitor - in other words the expenditure of UK residents travelling abroad before they leave the country which will include money spent on air fares for instance. It is possible to remove this element from the analysis and just concentrate on the visitor expenditure generated by the 'UK as a destination' in other words domestic overnight and same day visits and international inbound visits to the UK. If we calculate TDGVA on this basis then some of the distorting effects of air transport are less pronounced (although not entirely given the inclusion of inbound visitors). Figure 11 displays TDGVA on this basis for the Nuts 2 sub-regions. Inner London still has a dominant position in terms of TDGVA but the importance of Outer London (Heathrow) and Surrey and Sussex (Gatwick), for example, is now reduced. 
Figure 11: Tourism Direct GVA in sub-regions of the UK (Top 20 NUTS 2 regions) in 2008. (UK as a destination)

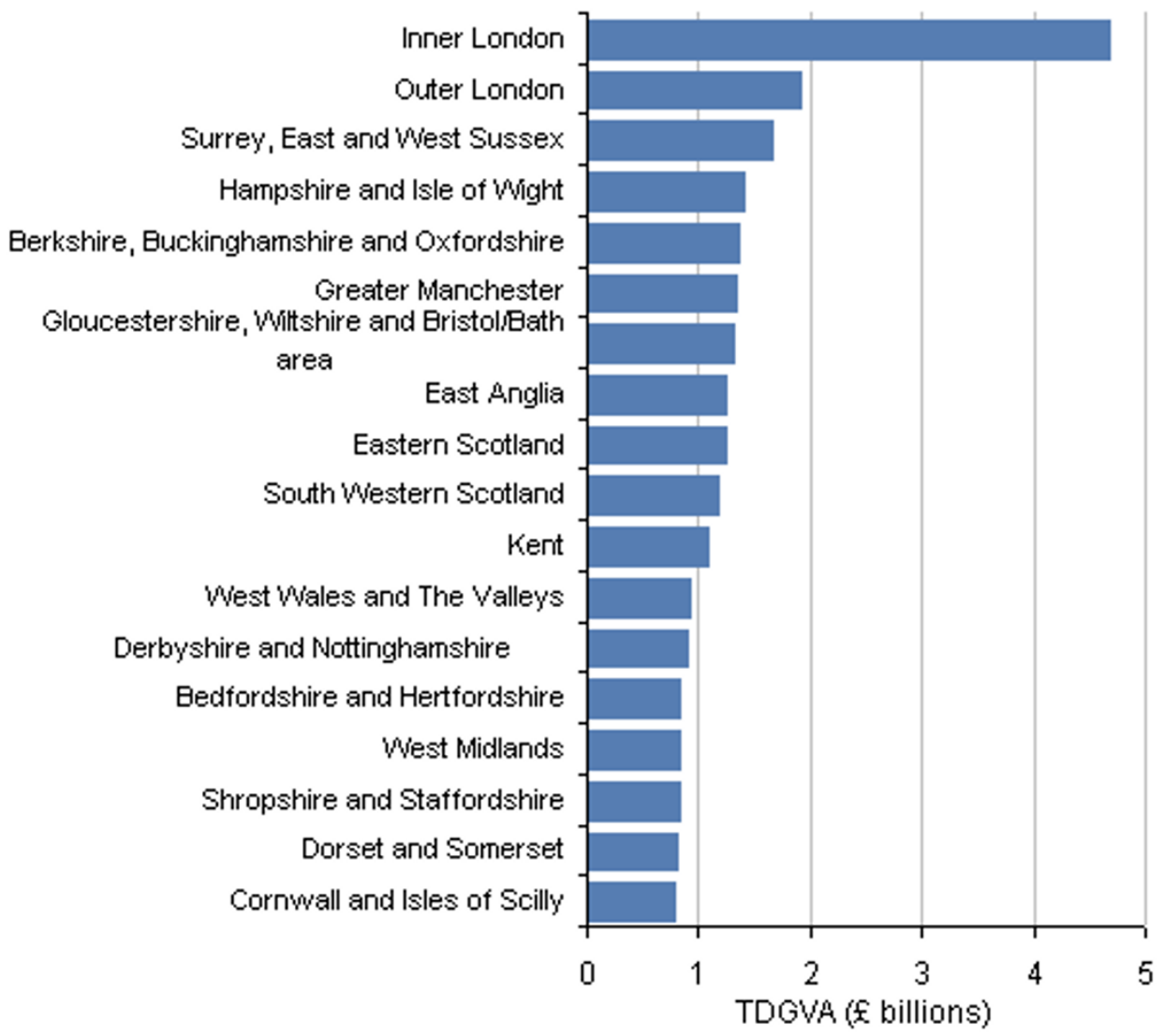

Source: Office for National Statistics

\section{Download chart}

\section{XLS XLS format}

$(24 \mathrm{~Kb})$

\section{NUTS 3 Analysis}

We have extended the reconciliation of the demand and supply sides of tourism to the NUTS 3 level and in the accompanying data tables for this release for the supply side analysis we have included the GVATI, TDGVA and Tourism Ratios at this level. These show some interesting results for the Tourism Ratios in particular where the relative importance of the tourism industries to NUTS 3 areas such as Cornwall and the Isles of Scilly, and the Isle of Anglesey and Gwynedd is revealed. In terms of the actual Tourism Direct GVA the larger economies of London and those areas with major airports is clearly visible. In the data tables we have charted some of the features of this NUTS 3 analysis in further detail. 


\section{Conclusions}

In this report the TIU has tried to provide as much detail as possible, within data constraints, on the patterns of tourism demand and supply, and the relationship between them, at a regional and subregional level. The methodology and analysis has been developed to be as consistent as possible with UK totals reported in the UK Tourism Satellite Account for 2008, with the afore-mentioned exception for TDGVA totals which are calculated in a different way to the TSA. It is important to stress again, however, that this analysis should not be considered a regional TSA as we are unable to adequately account for the supply of tourism characteristic products by industry at this level.

The results have shown that the major ports, particularly airports, have a distorting impact on the relationship between demand and supply and some of this is due to the large amount of tourism expenditure attributable to domestic outbound travel. Omitting this from the analysis gives a clearer picture of tourism expenditure in terms of the 'UK and its regions as a destination', including the relationship to supply. However domestic outbound expenditure is an important, internationally recognised, component of demand that should be considered in any analysis of the economic contribution of tourism.

It is hoped that this analysis provides an understanding of the dynamics of tourism supply and demand at a regional and sub-regional levels in the UK and that this is a valuable resource for tourism professionals at these levels. 